\title{
Decreased expression of S100A6 in oral squamous cell carcinoma
}

\author{
XIAO YANG*, KUI-JIE WEI*, LEI ZHANG, HONG-YA PAN, DONG-XIA YE, \\ LAI-PING ZHONG and ZHI-YUAN ZHANG
}

\begin{abstract}
Department of Oral and Maxillofacial Surgery, Ninth People's Hospital, School of Stomatology, Shanghai Jiao Tong University School of Medicine, Shanghai Key Laboratory of Stomatology, No. 639 Zhizaoju Road, Shanghai 200011, P.R China
\end{abstract}

Received March 8, 2010; Accepted May 27, 2010

DOI: 10.3892/or_00000882

\begin{abstract}
We previously established an in vitro cellular carcinogenesis model of oral squamous cell carcinoma (OSCC) with a line of human immortalized oral epithelia cells (HIOECs), a line of cancerous HB96 cells, and other cells (HB56 cells) at the early stage of carcinogenesis. In this study, comparative proteomic analysis identified a panel of differentially expressed proteins among these cells, and S100A6 was shown as one of the significantly downregulated proteins accompanying cellular transformation. S100A6 was further validated for its expression in the three cell lines and in the clinical samples of cancerous and paracancerous tissues from 30 primary OSCC patients. Western blot analysis and real-time PCR revealed the decreased S100A6 protein and mRNA levels in the cancerous HB56 and HB96 cells over HIOECs. Immunohistochemistry and real-time PCR also showed decreased S100A6 protein and mRNA levels in the cancerous tissues compared to the paracancerous tissues from OSCC patients. The results presented here suggest that the expression of S100A6 decreases along with the cancerization in OSCC both in vitro and in vivo.
\end{abstract}

\section{Introduction}

Oral squamous cell carcinoma (OSCC) is the most common malignant tumor in the oral and maxillofacial region. Although efforts has been made to improve the diagnosis and treatment of OSCC patients, the prognosis is still poor with a 5-year survival rate of approximately $50-60 \%(1,2)$. The mechanism of carcinogenesis of OSCC is still not very clear.

Correspondence to: Dr Lai-Ping Zhong, Department of Oral and Maxillofacial Surgery, Ninth People's Hospital, School of Stomatology, Shanghai Jiao Tong University School of Medicine, No. 639 Zhizaoju Road, Shanghai 200011, P.R China

E-mail: zhonglp@hotmail.com

*Contributed equally

Key words: oral squamous cell carcinoma, S100A6, in vitro cellular carcinogenesis model, proteomics
In vitro cellular model is an important object in understanding cellular events related to pathological or physiological conditions in humans. It is an indispensable study tool in investigation of molecular mechanisms, because it has many advantages such as homogeneity of cell population, accessibility, reproducibility, controllable growth rate, and hence enough amount of material for analysis (3). Thus, in vitro cellular carcinogenesis model is very important, especially for cancer research, not only on the aspect of molecular biomarkers, but also on the aspect of molecular mechanisms. Previously, we have successfully established a human immortalized oral epithelia cell line (HIOEC) by transfecting HPV16 E6/E7 gene to normal human oral epithelia cells (4), and a cancerous cell line (HB96) by treating the HIOEC with benzo[a]pyerene for 6 months, which can develop well to moderately differentiated squamous cell carcinoma in nude mice (5). An in vitro cellular carcinogenesis model of OSCC has also been established including the HIOECs, HB56 cells (at the early stage of cancerization), and HB96 cells (5). Based on this cellular carcinogenesis model, further comparative proteomic analysis is applied to identify the differentially expressed proteins, and the protein of S100A6 is one of them.

S100A6, an EF-hand calcium binding protein of the S100 protein family, is found in epithelial cells and fibroblasts (6) as well as in some neurons (7), Schwann cells and subpopulations of astrocytes (8). Most of previous studies on S100A6 have reported the increased expression of S100A6 in many malignancies, such as colorectal carcinoma/adenocarcinoma, gastric cancer, pancreatic ductal adenocarcinoma, cutaneous melanoma, thyroid papillary carcinoma, astrocytoma, choleteatoma, osteosarcoma, acute myeloid leukemia, and craniopharyngioma (9-18). However, decreased expression of S100A6 has also been reported in prostate cancer, thyroid anaplastic carcinoma, breast cancer, and hepatocellular carcinoma $(10,11,14,19-21)$. In this study, we described the significantly decreased expression of S100A6 in the HB96 cells compared with the HIOECs, as well as the S100A6 expression in OSCC cell lines and tissue samples.

\section{Materials and methods}

Cell cultures. The HIOECs, HB56 cells, and HB96 cells in the in vitro cellular carcinogenesis model of OSCC $(4,5)$ were 
used in this study. The HIOECs were cultured in the Defined keratinocyte-SFM (Gibco, USA). The HB56 and HB96 cells were cultured in the DMEM (Dulbecco's modified Eagle's medium, Gibco) supplemented with $10 \%$ fetal bovine serum, $1 \%$ glutamine, and $1 \%$ penicillin-streptomycin. All cells were cultured in a humidified atmosphere of $5 \% \mathrm{CO}_{2}$ at $37^{\circ} \mathrm{C}$.

Tissue samples. From February 2007 to July 2007, 30 patients with primary OSCC were involved in this study. Informed consent was obtained from each patient. None of them had received radiotherapy or chemotherapy before surgery. Surgical tissue samples of cancerous and paracancerous tissues were collected during surgery as previously described $(22,23)$. There were 21 males and 9 females, the age ranged from 31 to 84 years with a mean of 53.8 years. The sites of primary carcinoma were tongue $(n=17)$, buccal mucosa $(n=4)$, retromolar region $(n=3)$, floor of mouth $(n=3)$, gingiva $(n=2)$, and palatoglossal arch $(n=1)$. The stage of disease was determined according to the tumor-node-metastasis (TNM) staging system of the International Union Against Cancer (24). The histological grade was determined according to the WHO histological criteria (25).

Two-dimensional gel electrophoresis (2-DE) and liquid chromatography-tandem mass chromatography (LC-MS/MS). When the HIOECs and HB cells grew to $80 \%$ confluency, they were lysed in a 300- $\mu 1$ ice-cold lysis buffer containing $8 \mathrm{M}$ Urea, $65 \mathrm{mM}$ DTT, 4\% (w/v) CHAPS, $40 \mathrm{mM}$ Tris- $\mathrm{HCl}$, and $1 \mathrm{mM}$ PMSF. The protein concentration of the supernatant was determined using the Bradford dye-based protein assay reagent (Bio-Rad, USA). The first-dimensional isoelectric focusing (IEF) was performed with an IPGphor Isoelectric Focusing System (Amersham Biosciences, Sweden), 17-cm prefabricated immobilized $\mathrm{pH}$ gradient (IPG) strips with a linear $\mathrm{pH}$ range of 3-10 (Bio-Rad Catalog No. 163-2009). Total proteins $(400 \mu \mathrm{g})$ were mixed into a $500 \mu \mathrm{l}$ of rehydration solution containing $7 \mathrm{M}$ urea, $2 \mathrm{M}$ thiourea, 4\% CHAPS, $65 \mathrm{mM}$ DTT, and $0.001 \%$ bromophenol blue. After rehydration for $12 \mathrm{~h}$ with mineral oil covering the fluid, IEF was carried out at $17^{\circ} \mathrm{C}$ with a maximum current setting of $70 \mu \mathrm{A} /$ strip using the following conditions: $250 \mathrm{~V}$ for $30 \mathrm{~min}$ in linear mode, $1000 \mathrm{~V}$ for $1 \mathrm{~h}$ in rapid mode, $10000 \mathrm{~V}$ for $5 \mathrm{~h}$ in linear mode, $10000 \mathrm{~V}$ for $6 \mathrm{~h}$ in rapid mode, and then at $500 \mathrm{~V}$ with the temperature maintaining at $17^{\circ} \mathrm{C}$. The gel trips were equilibrated for $2 \times 15 \mathrm{~min}$ with equilibration buffer. Then, the second-dimensional SDS-PAGE was performed with a Hofer SE 600 Ruby System (Amersham Biosciences). The constant current was first $5 \mathrm{~mA} / \mathrm{gel}$ and then $30 \mathrm{~mA} / \mathrm{gel}$ until the bromophenol blue frontier reached the bottom of the gels. Two-dimensional standards were added to the protein samples as internal markers to determine the isoelectric point (pI) and molecular weight $(\mathrm{Mr})$. After 2-DE, the analytic gels were stained with ammoniacal silver nitrate for analysis. The preparative gel was stained with Coomassie brilliant blue. The silver stained gels were scanned using a GS710 imaging densitometer (Bio-Rad) in transmissive mode. Spot detection and matching were performed using PDQuest software version 7.3.0 (Bio-Rad). Expression intensity $>5.0$-fold or $<0.2$-fold was set as a threshold indicating significant changes. In-gel tryptic digest was performed using a digestion buffer comprising $0.1 \mu \mathrm{g} / \mu 1$ trypsin in $25-\mathrm{mM}$ ammonium bicarbonate. The peptide solutions were dried by vacuum centrifugation, desalted and cleaned using a C18 Ziptip (Millipore, USA). The peptide mixtures were separated and identified by a Finnigan LTQ mass spectrometercoupled with a Surveyor HPLC system (ThermoQuest, USA). Microcore RP column (C18 0.15x150 mm, ThermoHypersil, USA) was used to separate the protein digests, the trap column was Zorbax 300SB-C18 peptide traps (Agilent Technologies, USA). Solvent A was $0.1 \%$ formic acid, and solvent B was $0.1 \%$ formic acid in $100 \%$ acetonitrile. The gradient was increased linearly from 3 to $38 \%$ solvent $\mathrm{B}$ in $50 \mathrm{~min}$. The peptides were electrosprayed directly into the mass spectrometer with the application of spray voltage of $3.2 \mathrm{kV}$ and with the capillary temperature $170^{\circ} \mathrm{C}$. The full scan ranged from $\mathrm{m} / \mathrm{z}$ 400 to 2000 . Protein identification using MS/MS raw data was performed with SEQUEST program in the BioWorks 3.1 software suite (University of Washington, licensed to Thermo Finnigan) based on the IPI Human database version 3.15.1. Trypsin was selected as protein cleavage specificity. Both $b$ ions and y ions were also included in the database search. Protein identification results were filtered with the Xcorr ( $\geq 1.9$ for a $1+$ tryptic peptide, $\geq 2.2$ for a $2+$ tryptic peptide, $\geq 3.75$ for a $3+$ tryptic peptide) and $\Delta \mathrm{Cn}(\geq 0.1)$.

Western blot analysis. Total protein was prepared from the cultured cells grown to $80 \%$ confluency, lysed in icecold $2 \mathrm{X}$ lysis buffer containing $125 \mathrm{mM}$ Tris- $\mathrm{HCl}$ (pH 6.8), $5 \% \mathrm{w} / \mathrm{v}$ SDS, and $24.75 \%$ glycerol as we previously described $(4,5)$. Each sample $(2 \mu 1)$ was used for protein concentration assessment using the Bradford assay (Bio-Rad). Extracted proteins (50 $\mu \mathrm{g} / \mathrm{lane})$ were separated using 12\% SDS-PAGE. Proteins were then electrophoretically transferred onto the PVDF membranes using a wet transfer system (Invitrogen, USA). The membranes were blocked with blocking buffer containing $5 \%$ dry milk in PBS with $0.1 \%$ Tween-20 and incubated overnight with the primary antibodies of monoclonal anti-mouse S100A6 antibody (clone CACY-100, Abcam, UK) at 1:200 dilution, then incubated with fluorescent-based secondary antibodies at 1:1000 dilution for $1 \mathrm{~h}$. Finally, the immunoreactive bands were scanned and analyzed using the Odyssey Infrared Imaging System (LICOR Biosciences, USA). B-actin was used as internal control protein.

Real-time RT-PCR. Total RNA of cultured cells was isolated from cells grown to $80 \%$ confluency using TRIzol reagent according to the manufacturer's instructions. The procedure of total RNA extraction and cDNA synthesis was performed as we previously described $(22,23)$. The M-MLV (Promage, USA) and random primers (Amersham Biosciences, USA) were used to perform reverse transcription with $2 \mu \mathrm{g}$ total RNA. The alterations of S00A6 was confirmed using fluorescent-based real-time PCR quantification (SYBR Premix Ex Taq, Takara, Japan) using the Thermal Cycler Dice $^{\text {TM }}$ Real-Time System (Takara). The primer sequences of S100A6 (NM_014624) were designed by primer premier 5.0 (Premier Biosoft International, CA), forward primer 5'-G GGAGGGTGACAAGCACAC-3', reverse primer 5'-AGCT TCGAGCCAATGGTGAG-3', the length of PCR product was 
Table I. The differentially expressed proteins identified in the HIOECs, HB56 and HB96 cells.

Name of cells Abbreviations of gene names according to the identified differentially expressed proteins

HIOECs $\quad$ ACP1, ANXA1, ECH1, ETHE1, GLO1, GRB2, HCC1, ISG15, KRT7, NDUFV2, PCBP2, PFN2, PRDX1, PSMB3,Q8N849, RANBP1, RPS12, SOD2, S100A6, S100A8, TPD52L2, TPI1, TXNL4A, VBP1, ZYX, $44 \mathrm{kDa}$ protein-ENSP00000319797

HB56 cells ANXA2, CFL, KRT17

HB96 cells ANXA2, CAPZA1, CTSB, EEF2, ERH, GAPDH, GNB1, LASP1, LGALS1, M6PRBP1, PDHB, PFN2, RANBP1, RPP2, SERPINB5, STMN1, TUBB2C, TUFM, UCHL1
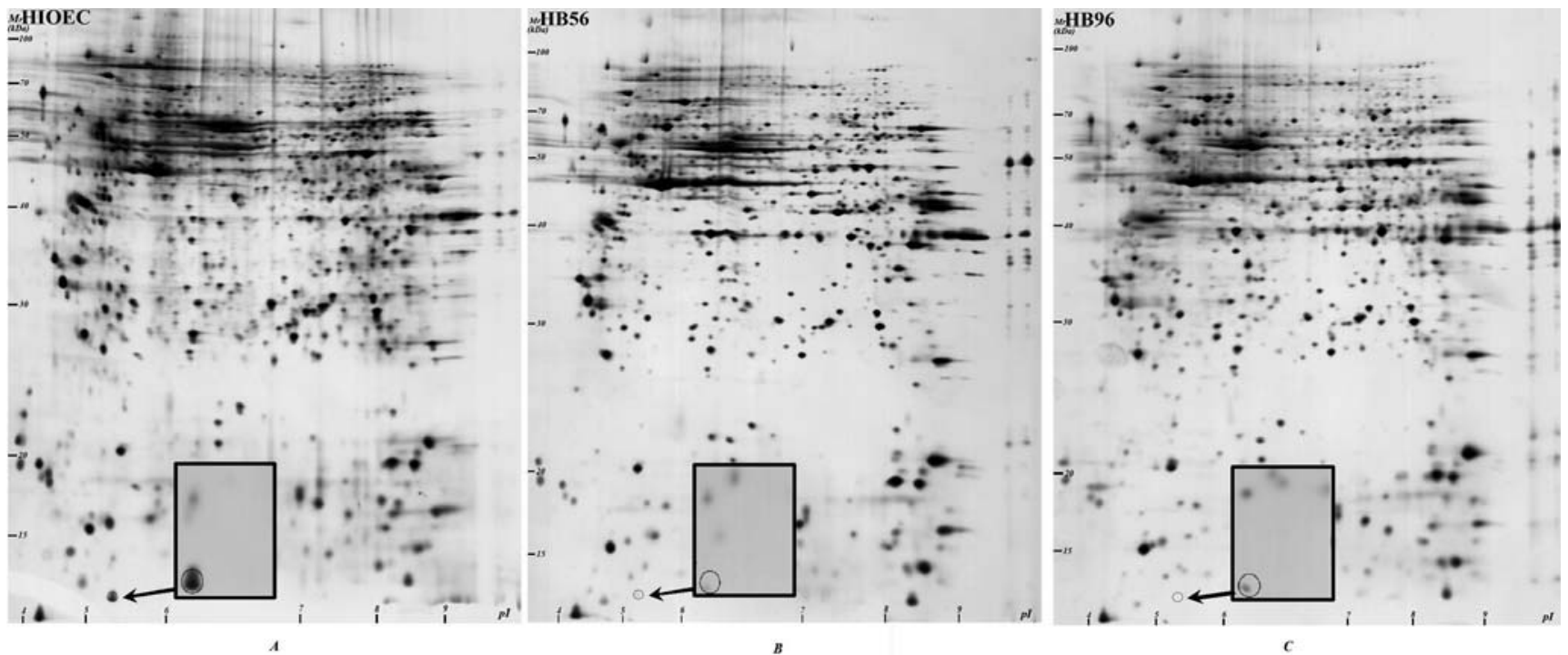

Figure 1. (A) 2-DE electrophotogram of the protein profile in the HIOECs. (B) 2-DE electrophotogram of the protein profile in the HB56 cells. (C) 2-DE electrophotograms of the protein profile in the HB96 cells. The IEF was pH 3-10. The differentially expressed protein spot of S100A6 was marked with a circle.

$79 \mathrm{bp}$. The primer sequences of $\beta$-actin were forward primer 5'-TCACCCACACTGTGCCCATCTACGA-3', reverse primer 5'-CAGCGGAACCGCTCATTGCCAATGG-3', the length of PCR product was $100 \mathrm{bp}$. The conditions for PCR reactions were: $95^{\circ} \mathrm{C}$ for $10 \mathrm{sec}$ followed by 40 cycles of denaturation at $95^{\circ} \mathrm{C}$ for $5 \mathrm{sec}$, annealing elongation at $60^{\circ} \mathrm{C}$ for $30 \mathrm{sec}$. The relative quantification of S100A6 mRNA level compared with internal control gene $B$-actin was calculated according to the $2^{-\Delta \Delta \mathrm{Ct}}$ method described by Livak and Schmittgen (26). $-\Delta \Delta \mathrm{Ct}=\left[\mathrm{Ct}_{\text {(cancerous tissue B-actin) }}-\mathrm{Ct}_{\text {(cancerous }}\right.$ tissue $\mathrm{S100A6)}] /\left[\mathrm{C}_{\mathrm{t}(\text { paracancerous tissue B-actin) }}-\mathrm{Ct}_{\text {(paracancerous tissue S100A6) }}\right]$.

All the samples were run in duplicates and the relative quantification of each target gene expression was done twice.

Immunohistochemistry. The procedure of immunohistochemistry was performed as we previously described $(22,27)$. Briefly, after deparaffinization and endogenous peroxidase blocked, the sections were heated by water bath at $98^{\circ} \mathrm{C}$ with $0.01 \mathrm{M}$ citrate buffer solution ( $\mathrm{pH} \mathrm{6.0)}$ for $20 \mathrm{~min}$, then incubated with the monoclonal anti-mouse S100A6 antibody (clone CACY-100, Abcam, UK) at 1:100 dilution overnight at $4^{\circ} \mathrm{C}$, and visualized using DAB detection kit (Dako Cyto- mation, Denmark). Negative control was prepared using PBS instead of primary antibody. Microscopic examination was performed by two pathologists and all samples were blinded. The immunoreactive positive score was determined based on the proportion of stained cells on a scale of negative to strong as follows: negative, $0 \%$ of stained cells with score of 0 ; weak, $1-25 \%$ of stained cells with score 1 ; moderate, $26-50 \%$ of stained cells with score 2 ; and strong, $>50 \%$ of stained cells with score 3 .

Statistical analysis. The data were analyzed using the statistical software of SPSS10.0 for Windows (SPSS Inc., USA). The statistical difference of the initial data was analyzed using the non-parametric tests. When the P-value was $<0.05$, the difference was regarded as statistically significant.

\section{Results}

2-DE and LC-MS/MS. Using the two-dimensional gel electrophoresis, we compared the protein profiles between the HIOECs, HB56, and HB96 cells. There were $>50$ protein spots up- or down-regulated in the protein profiles between 


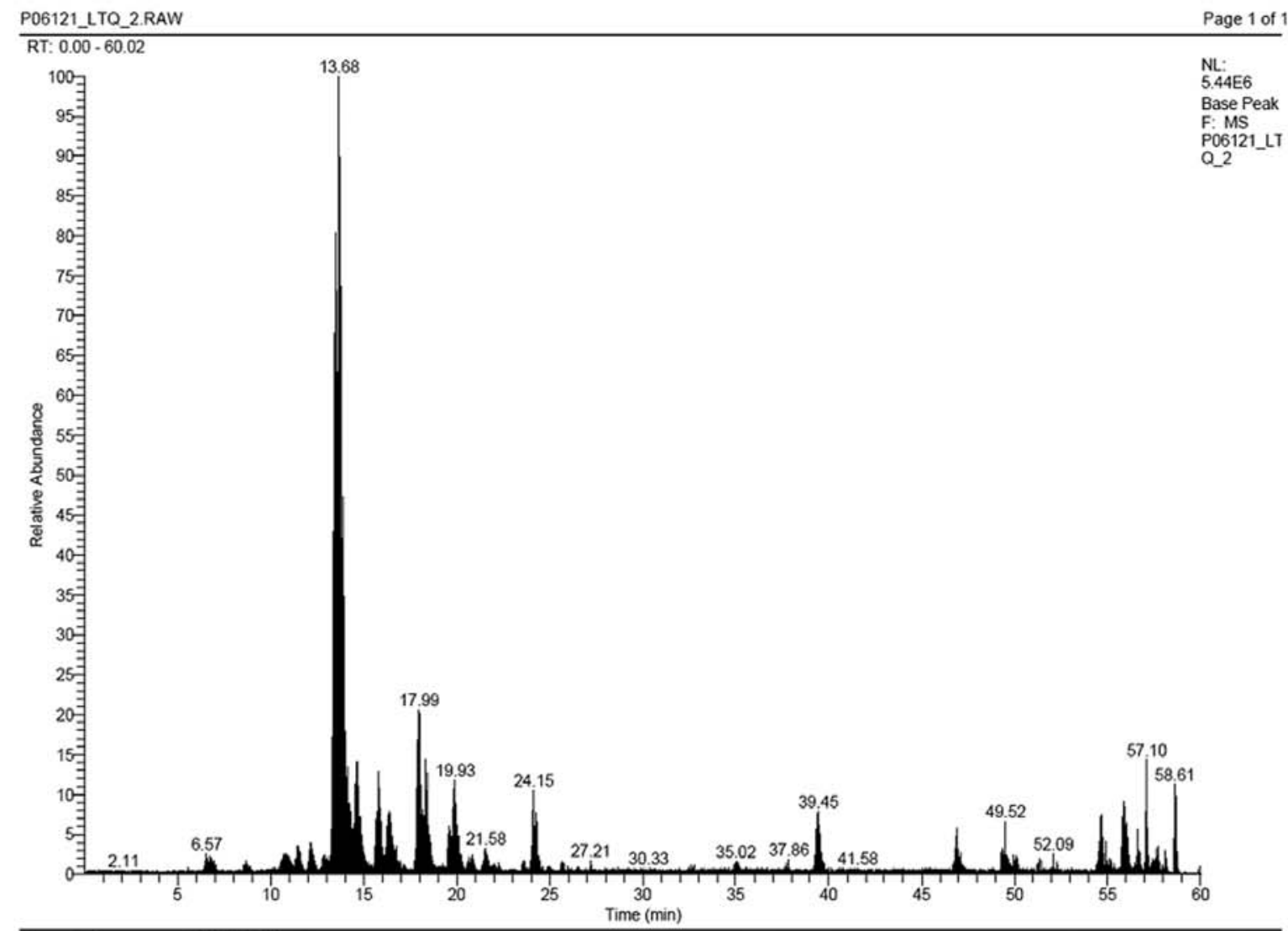

BioworksBrowser rev. 3.1 SR1 Alpha 7

Page 1 of

Dta: 06121 LTQ 2.4436 .4436 .2

Eecursor mass: 681.46

Mass type: Average
Yod's: ( $\left.\mathbb{N}^{*}+15.9994\right) \quad \mathrm{C}=160.1652$

Ion series for charge: +1

\begin{tabular}{|c|c|c|}
\hline A ions & B ions & $Y$ ions \\
\hline $\mathrm{z}$ & 130.12 & \\
\hline $\mathrm{L}$ & 243.28 & 1230.46 \\
\hline 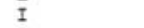 & 356.44 & 1117.30 \\
\hline Q & 484.57 & 1004.14 \\
\hline$\hat{\mathrm{z}}$ & 612.74 & 876.01 \\
\hline $\mathrm{z}$ & 741.86 & 747.84 \\
\hline L & 855.01 & 618.72 \\
\hline $\mathrm{T}$ & 956.12 & 505.56 \\
\hline & 1069.28 & 404.46 \\
\hline & 1126.33 & 291.30 \\
\hline 5 & 1213.41 & 234.25 \\
\hline 8 & - & 147.17 \\
\hline
\end{tabular}

\#4436-4436 RT:0.00-0.00 NL: 3.69E3

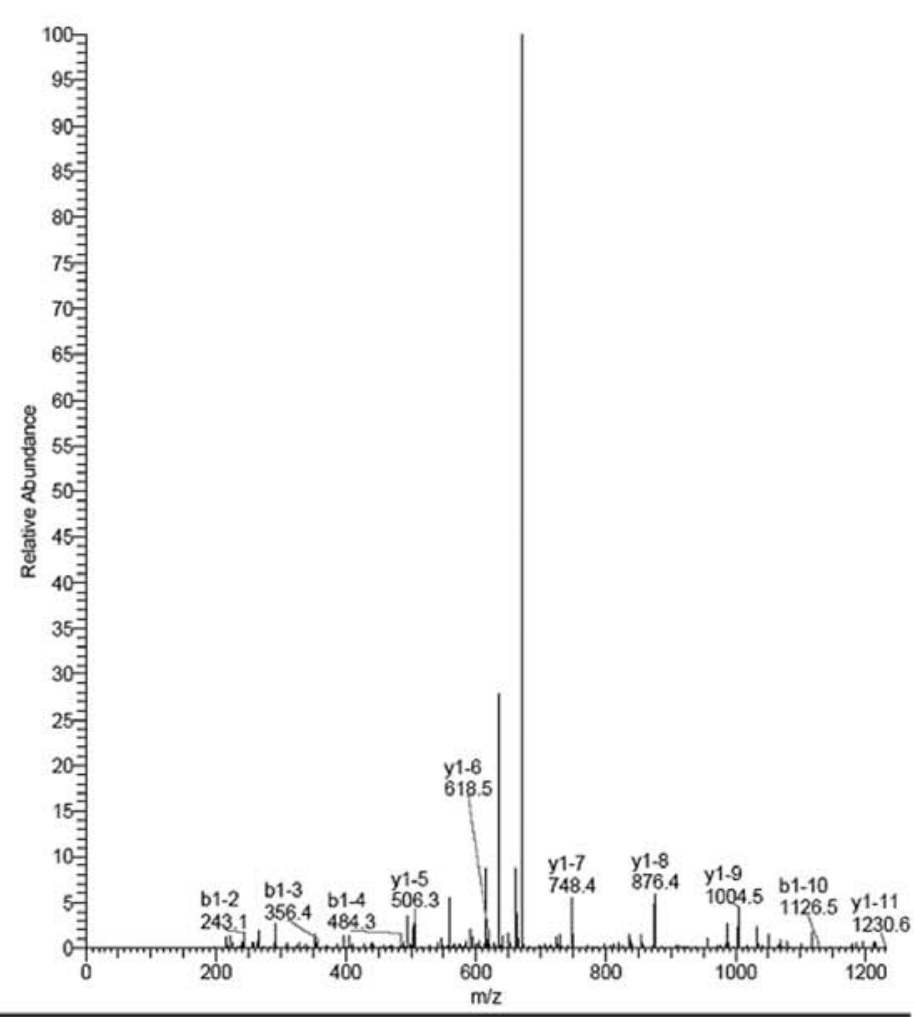

BioworksBrowser rev. 3.1 SR1 Alpha 7 


\begin{tabular}{|c|c|c|c|c|c|c|c|c|c|c|c|c|c|}
\hline Reference & PepCount & $\begin{array}{l}\text { UniquePep } \\
\text { Count }\end{array}$ & $\begin{array}{l}\text { Cover } \\
\text { Percent }\end{array}$ & MW & PI & Identified & Name & & & & & & \\
\hline \multirow[t]{2}{*}{ File, Scan(s) } & Sequence & $\mathrm{MH}^{+}$ & $\operatorname{Diff}\left(\mathrm{MH}^{+}\right)$ & Clarge & Rank & $\mathrm{XC}$ & DeltaCn & $\mathrm{Sp}$ & $\mathrm{RSp}$ & Ions & PI & $\begin{array}{l}\text { Group } \\
\text { Count }\end{array}$ & $\begin{array}{l}\text { Protein } \\
\text { Count }\end{array}$ \\
\hline & 14 & 6 & $36.67 \%$ & 10179.74 & 5.32 & \multicolumn{8}{|c|}{$\begin{array}{l}\text { IPI:IPI00027463. I|SWISS-PROT:P06703|TREMBL:Q5RHS4|ENSEMBL: } \\
\text { ENS P00000349740|REFSEQ:NP_055439|H-INV:HIT000030408;HIT000034143| } \\
\text { VEGA:OTTHUMP00000015472;OTTHUMP00000015473 Tax Id=9606 Calcyclin }\end{array}$} \\
\hline P06121_LTQ_2,4436 & K.ELIQKELTIGSKL & 1359.5939 & -2.2701 & 2 & 1 & 4.0014 & 0.446 & 518.7 & 1 & 17722 & 6.24 & 1 & 1 \\
\hline P06121_LTQ_2,4457 & K.ELIQKELTIGSKL & 1359.5939 & 1.1019 & 2 & 1 & 2.9989 & 0.4417 & 949.5 & 1 & 1922 & 6.24 & 1 & 1 \\
\hline P06121_LTQ_2,2763 & KELTIGSKLL & 747.8602 & -1.6058 & 1 & 1 & 1.9799 & 0.1184 & 166.4 & 1 & $8 \mid 12$ & 6.1 & 1 & 1 \\
\hline P06121_LTQ_2,3174 & K.KELKELIQK.E & 1129.3751 & 0.4621 & 2 & 1 & 2.5695 & 0.1241 & 1188.6 & 1 & $14 \mid 16$ & 8.5 & 1 & 1 \\
\hline P06121_LTQ_2,2598 & K.LQDAELAR.L & 916.0142 & -1.4148 & 1 & 1 & 2.1236 & 0.1418 & 453.1 & 1 & $1 q_{14}$ & 4.37 & 1 & 1 \\
\hline P06121_LTQ_2,2785 & K.LQDAELAR.L & 916.0142 & 0.0352 & 2 & 1 & 2.5083 & 0.3172 & 8299 & 1 & $13 \mid 14$ & 4.37 & 1 & 1 \\
\hline P06121_LTQ_2,2796 & K.LQDAELAR.L & 916.0142 & -0.8498 & 2 & 1 & 2.6562 & 0.3331 & 1059.2 & 1 & $13 \mid 14$ & 4.37 & 1 & 1 \\
\hline P06121_LTQ_2,3104 & K.LQDAELAR.L & 916.0142 & 0.4872 & 2 & 1 & 2.5288 & 0.2624 & 871.5 & 1 & $13 \mid 14$ & 4.37 & 1 & 1 \\
\hline P06121_LTQ_2,3709 & K.LQDAEIAR.L & 916.0142 & 0.292 & 2 & 1 & 2.4984 & 0.3235 & 589.1 & 3 & $12 \mid 14$ & 4.37 & 1 & 1 \\
\hline P06121_LTQ_2,9880 & K.LQDAELAR.L & 916.0142 & -0.8468 & 2 & 1 & 2.2996 & 0.2471 & 873.5 & 1 & $13 \mid 14$ & 4.37 & 1 & 1 \\
\hline P06121_LTQ_2,10507 & K.LQDAELAR.L & 916.0142 & -1.6258 & 2 & 1 & 2.3119 & 0.2677 & 819 & 1 & $13 \mid 14$ & 4.37 & 1 & 1 \\
\hline P06121_LTQ_2,2147 & RLM*EDLDRNK.D & 1150.2883 & -0.7547 & 2 & 1 & 2.5105 & 0.1242 & 324.4 & 1 & $12 \mid 16$ & 4.56 & 1 & 1 \\
\hline P06121_LTQ_2,3017 & RLMEDLDRNKD & 1134.2889 & 0.1969 & 2 & 1 & 2.7315 & 0.1776 & 1202.1 & 1 & 1416 & 4.56 & 1 & 1 \\
\hline P06121_LTQ_2,3027 & RLMEDLDRNKD & 1134.2889 & 0.9299 & 2 & 1 & 2.5598 & 0.2732 & 1374 & 1 & $14 \mid 16$ & 4.56 & 1 & 1 \\
\hline
\end{tabular}

\section{MACPLDQAIGLLVAIFHKYSGREGDKHTLSK $\underline{\text { ELKELIQKELTIGSKLQDAEIARLMED }}$} LDRNKDQEVNFQEYVTFLGALALIYNEALKG

Figure 2. (B) Protein identification using MS/MS raw data was performed with Sequest program in the BioWorks 3.1 software suite based on the IPI Human database version 3.15.1. Matched peptides are shown in bold and underlined.

the HIOECs, HB56, and HB96 cells (Table I). Among these protein spots, one significantly down-regulated protein in the HB cells compared with the HIOECs (marked with a circle in Fig. 1), was identified as S100A6 protein using LCMS/MS. The peptides fingerprint and the matched peptides are shown in Fig. 2. These results were obtained by searching the IPI Human database version 3.15.1 with SEQUEST program in the BioWorks 3.1 software suite (University of Washington, licensed to Thermo Finnigan).

Protein expression and $m R N A$ level of S100A6 in the HIOECs, HB56 cells, and HB96 cells. Using Western blot analysis, the protein expression of S100A6 in the HB56 and HB96 cells was found decreased compared with the HIOECs normalized against $B$-actin (Fig. 3A and B). The protein expression of S100A6 in the cellular carcinogenesis model was identical to the comparative proteomic analysis result.
The relative mRNA level of S100A6 was also found decreased in the HB56 and HB96 cells compared with the HIOECs normalized against $\beta$-actin using real-time PCR detection (Fig. 3C).

Protein expression and mRNA level of S100A6 in tissue samples. Using immunohistochemistry, the paracancerous tissues were found strongly immunoreactive for S100A6 in the cellular membrane and cytoplasm. The positive rate of S100A6 protein in the paracancerous tissues was $96.7 \%$ (29/30); the positive rate of S100A6 in the cancerous tissues was $70.0 \%(21 / 30)$. The positive score of S100A6 in the cancerous tissues $(1.17 \pm 0.91)$ was significantly lower than that in the paired paracancerous tissues $(2.10 \pm 0.92)$ (Wilcoxon Signed Ranks test, Z=-4.365, P<0.001) (Table II). Although decreased expression of S100A6 was found in the cancerous tissues of different pathological differentiation 
A

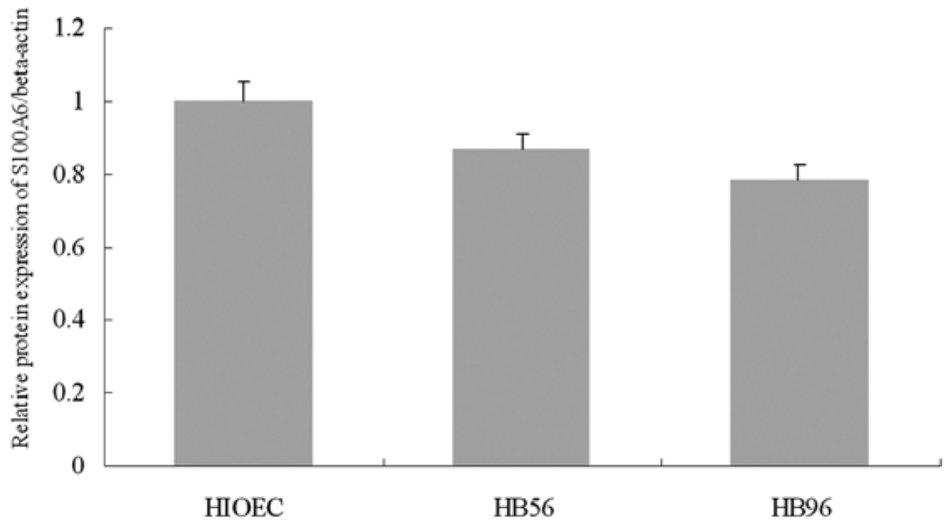

B

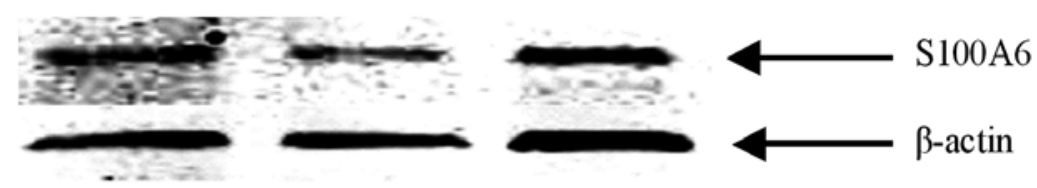

HIOEC

HB56

HB96

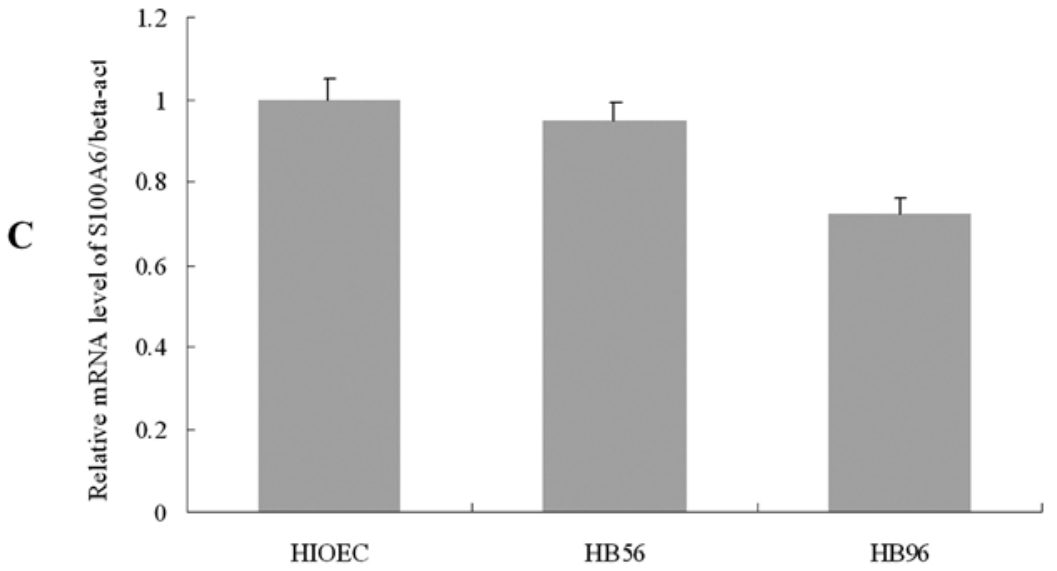

Figure 3. (A and B) Western blot analysis of S100A6 protein expression in the HIOECs, HB56 cells, and HB96 cells. The S100A6 protein expression for each sample was normalized against B-actin. Decreased S100A6 protein expression was found in both the HB56 and HB96 cells. (C) S100A6 mRNA level in the HIOECs, HB56 cells, and HB96 cells, which was normalized against B-actin. Decreased S100A6 mRNA level was also found in both of the HB56 and HB96 cells.

Table II. The immunohistochemical S100A6 positive scores in the different types of tissues from oral squamous cell carcinoma patients.

\begin{tabular}{lcrrr}
\hline & & \multicolumn{2}{c}{ S100A6 positive score } \\
\cline { 3 - 5 } Type of tissue & Total cases & 0 & 1 & 2 \\
\hline No. of paracancerous tissue & 30 & 1 & 8 & 8 \\
No. of cancerous tissue & 30 & 9 & 8 & 13 \\
\hline
\end{tabular}

Wilcoxon Signed Ranks Test, the difference of S100A6 positive scores between the cancerous and paracancerous tissues was significant with $\mathrm{Z}=-4.365, \mathrm{P}<0.001$.

grade, the correlation between the positive score of S100A6 protein expression and pathological differentiation grade was not significant $(\mathrm{P}=0.850)$ (Fig. 4). Furthermore, no significant relationship was found between the S100A6 positive score with $\mathrm{T}$ stage $(\mathrm{P}=0.529), \mathrm{N}$ stage $(\mathrm{P}=0.930)$, clinical stage $(\mathrm{P}=0.4892)$, smoking $(\mathrm{P}=0.412)$ and drinking $(\mathrm{P}=0.946)$ exposure (Table III).

The good efficacy and specificity of real-time PCR was confirmed by melting curve and $3 \%$ agarose gel electrophoresis. The distribution of relative quantification data 
A

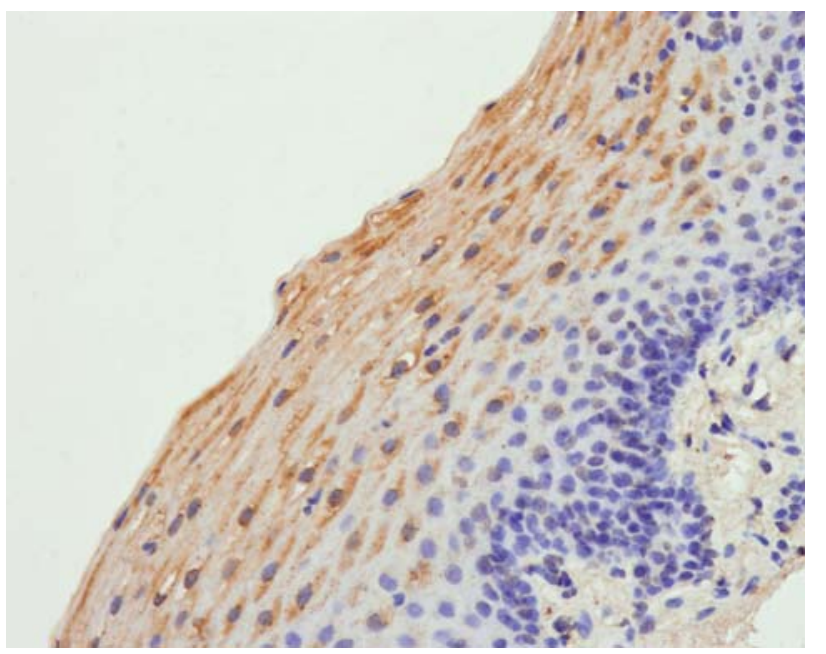

C

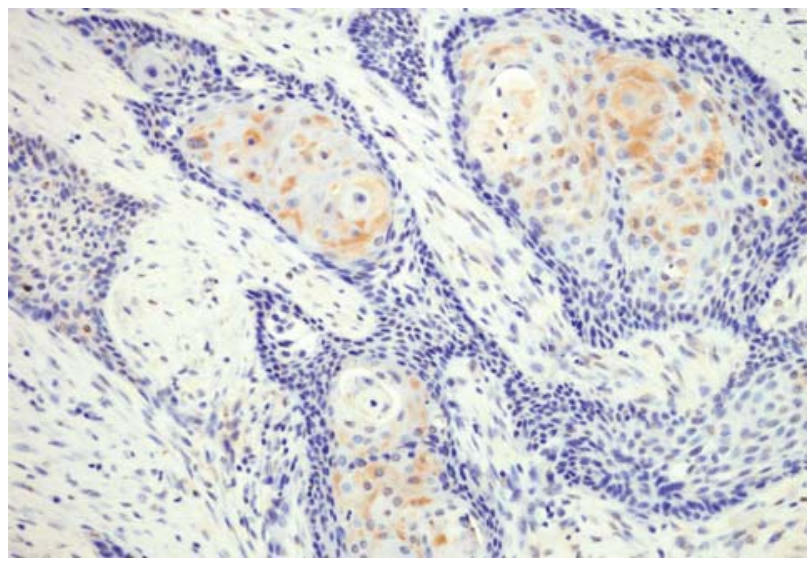

B

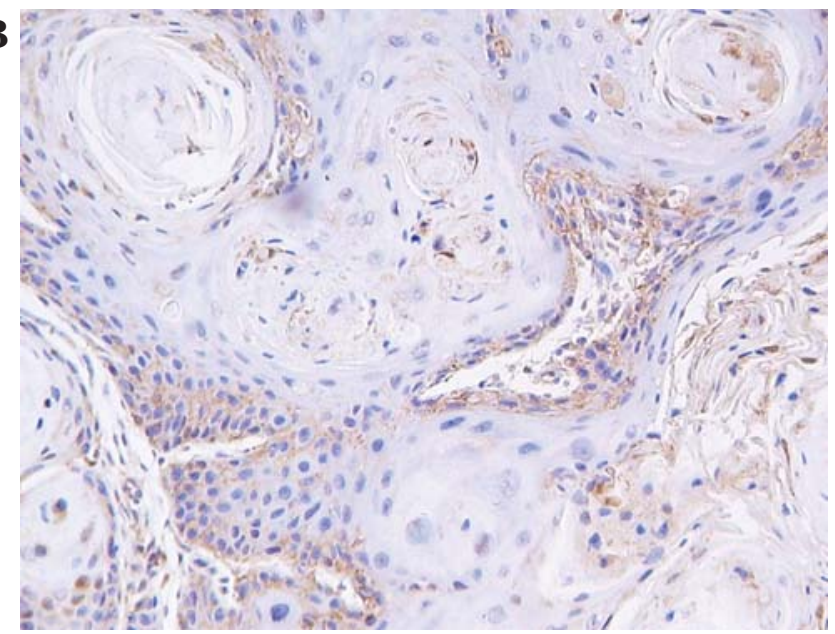

D

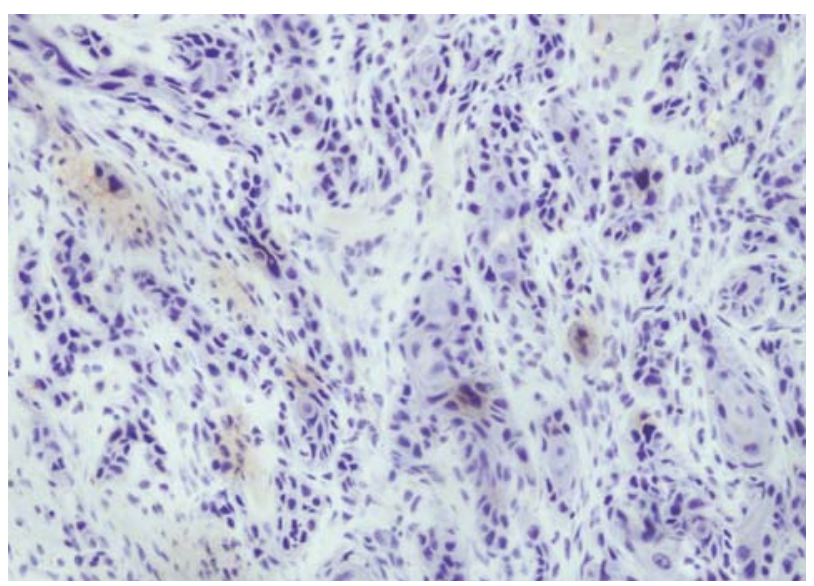

Figure 4. Immunoreactions of S100A6 protein was strong (A) in the paracancerous tissues (x200), and relatively low in the well- (B), moderately- (C), and poorly- (D) differentiated cancerous tissues (x200). The location of the protein immunoreaction was the cellular membrane and the cytoplasm.

of S100A6 mRNA level was firstly tested using one-sample Kolmogorov-Smirnov test, and the distribution was normal $(\mathrm{P}=0.258)$, but the $\mathrm{CV}$ value was $83.1 \%$. Therefore, nonparametric analysis was performed. By descriptive statistics, S100A6 mRNA level in the cancerous tissues was 0.753 -fold lower than that in the paracancerous tissues, with standard error value of 0.114 , standard deviation of 0.626 , and $95 \%$ of confidence interval for mean from 0.519 to 0.987 . S100A6 mRNA level decreased significantly in the cancerous tissues compared with the paracancerous tissues $(\mathrm{t}=-2.163, \mathrm{P}=0.039)$. The correlation between the clinicopathological characteristics and the relative S100A6 mRNA level was analyzed (Table III), and no significant difference could be found, for $\mathrm{T}$ stage $(\mathrm{P}=0.558)$, $\mathrm{N}$ stage $(\mathrm{P}=0.708)$, clinical stage $(\mathrm{P}=0.755)$, pathological differentiation grade $(\mathrm{P}=0.953)$, smoking $(\mathrm{P}=0.950)$, and drinking $(\mathrm{P}=0.641)$.

\section{Discussion}

Proteomic analysis is an accurate, sensitive and high-throughput protein identification strategy. In the research of the molecular mechanisms of diseases, comparative proteomic analysis has been used as an innovative method to investigate the protein expressions between cancerous and normal tissues/ cells. Several studies on OSCC have reported the application of comparative proteomic analysis in identifying differe- ntially expressed proteins in tissue $(28-30)$, cell $(31,32)$, serum (33-35), and saliva $(36,37)$. Many differentially expressed proteins have been identified between the cancerous and normal samples. Tissue, serum and saliva samples from different subjects generally have individual variations, and their availability is limited. In contrast, cell line offers a stable supply of homogeneous samples; further in vitro cellular carcinogenesis model offers a very useful and important tool for cancer research, especially on the aspects of molecular biomarkers and their mechanisms. It is an indispensable study tool in investigations of molecular mechanisms, because it has many advantages such as homogeneity of cell population, accessibility, reproducibility, controllable growth rate, and hence enough amount of material for analysis (4). Park et al (38) has established an in vitro multistep carcinogenesis model for OSCC from immortalized normal human oral keratinocytes. This model has been used for the in vitro investigation of gene expressions $(39,40)$. However, no systematic study of the total protein expression is reported.

Our previous work established an in vitro cellular carcinogenesis model of OSCC, including three kinds of HIOEC, HB56, and HB96, whose biological characteristics have been previously described including cell morphology, cell ultrastructure, cell growth, cell circle analysis, immunocytochemistry, in vitro invasion ability, and tumorigenicity. In mice injected subcutaneously with HIOECs, no neoplasm 
Table III. The correlation between the status of S100A6 expression and the clinicopathological characteristics of oral squamous cell carcinoma patients.

\begin{tabular}{|c|c|c|c|c|c|c|c|}
\hline Classification & Case no. & $\begin{array}{l}\text { Relative } \\
\text { mRNA level }\end{array}$ & $\begin{array}{l}\text { Non-parametric } \\
\text { test value }\end{array}$ & P-value & $\begin{array}{c}\text { Cancerous protein } \\
\text { positive score }\end{array}$ & $\begin{array}{l}\text { Non-parametric } \\
\text { test value }\end{array}$ & P-value \\
\hline \multicolumn{8}{|l|}{ Smoking } \\
\hline Yes & 13 & $0.723 \pm 0.505$ & \multirow[t]{2}{*}{$Z=-0.063$} & \multirow[t]{2}{*}{0.950} & $1.00 \pm 0.91$ & \multirow[t]{2}{*}{$Z=-0.820$} & \multirow[t]{2}{*}{0.412} \\
\hline No & 17 & $0.776 \pm 0.720$ & & & $1.29 \pm 0.92$ & & \\
\hline \multicolumn{8}{|l|}{ Drinking } \\
\hline Yes & 12 & $0.754 \pm 0.477$ & \multirow[t]{2}{*}{$Z=-0.466$} & \multirow[t]{2}{*}{0.641} & $1.17 \pm 1.03$ & \multirow[t]{2}{*}{$Z=-0.067$} & \multirow[t]{2}{*}{0.946} \\
\hline No & 18 & $0.752 \pm 0.722$ & & & $1.17 \pm 0.86$ & & \\
\hline \multicolumn{8}{|l|}{ T stage } \\
\hline $\mathrm{T} 1$ & 6 & $1.052 \pm 1.153$ & \multirow{4}{*}{$\begin{array}{c}\chi^{2}=2.072 \\
\mathrm{df}=3\end{array}$} & 0.558 & $1.17 \pm 0.98$ & & 0.529 \\
\hline $\mathrm{T} 2$ & 13 & $0.702 \pm 0.515$ & & & $1.07 \pm 0.86$ & \multirow{3}{*}{$\begin{array}{c}\chi^{2}=2.216 \\
\mathrm{df}=3\end{array}$} & \\
\hline $\mathrm{T} 3$ & 4 & $0.469 \pm 0.294$ & & & $1.75 \pm 0.50$ & & \\
\hline $\mathrm{T} 4$ & 7 & $0.752 \pm 0.259$ & & & $1.00 \pm 1.15$ & & \\
\hline \multicolumn{8}{|l|}{$\mathrm{N}$ stage } \\
\hline N0 & 16 & $0.821 \pm 0.817$ & \multirow{2}{*}{$Z=-0.374$} & \multirow{2}{*}{0.708} & $1.19 \pm 0.98$ & \multirow[t]{2}{*}{$Z=-0.088$} & \multirow[t]{2}{*}{0.930} \\
\hline N1-2 & 14 & $0.674 \pm 0.305$ & & & $1.14 \pm 0.86$ & & \\
\hline \multicolumn{8}{|l|}{ Clinical stage } \\
\hline I & 5 & $1.151 \pm 1.260$ & \multirow{4}{*}{$\begin{array}{c}\chi^{2}=3.511 \\
\mathrm{df}=3\end{array}$} & \multirow{4}{*}{0.319} & $1.40 \pm 0.89$ & \multirow{4}{*}{$\begin{array}{c}\chi^{2}=2.424 \\
\mathrm{df}=3\end{array}$} & \multirow{4}{*}{0.489} \\
\hline II & 8 & $0.663 \pm 0.612$ & & & $0.75 \pm 0.89$ & & \\
\hline III & 2 & $0.341 \pm 0.074$ & & & $1.50 \pm 0.71$ & & \\
\hline IV & 15 & $0.723 \pm 0.292$ & & & $1.27 \pm 0.96$ & & \\
\hline I + II & 13 & $0.850 \pm 0.899$ & \multirow[t]{2}{*}{$Z=-0.523$} & \multirow[t]{2}{*}{0.601} & $1.00 \pm 0.91$ & \multirow[t]{2}{*}{$Z=-0.820$} & \multirow[t]{2}{*}{0.412} \\
\hline $\mathrm{III}+\mathrm{IV}$ & 17 & $0.680 \pm 0.302$ & & & $1.29 \pm 0.92$ & & \\
\hline \multicolumn{8}{|l|}{$\begin{array}{l}\text { Pathological } \\
\text { differentiation } \\
\text { grade }\end{array}$} \\
\hline Well & 12 & $0.652 \pm 0.301$ & \multirow{3}{*}{$\begin{array}{c}\chi^{2}=0.097 \\
\mathrm{df}=2\end{array}$} & \multirow{3}{*}{0.953} & $1.08 \pm 0.90$ & \multirow{3}{*}{$\begin{array}{c}\chi^{2}=0.326 \\
\mathrm{df}=2\end{array}$} & \multirow{3}{*}{0.850} \\
\hline Moderately & 15 & $0.720 \pm 0.473$ & & & $1.27 \pm 0.96$ & & \\
\hline Poorly & 3 & $1.319 \pm 1.753$ & & & $1.00 \pm 1.00$ & & \\
\hline
\end{tabular}

formed. In mice injected with HB56 cells, the neoplasms formed had an intact envelope with 2-3 layers of epithelial cells under the envelope, and massive keratinocytes under the epithelial cells, parakeratosis could also be found in some keratinocytes with few atypical hyperplasia. In the mice injected with HB96 cells, the neoplasm formed was typical squamous cell carcinoma; the differentiation of tumor cells was good to moderate with obvious atypical hyperplasia and pathological mitosis $(4,5)$. Using this in vitro cellular carcinogenesis model, more than 40 differentially expressed proteins were identified by comparative proteomic analysis during the cancerization process. S100A6, being one of the differentially expressed proteins, was identified in the HIOECs, indicating the decreased expression of S100A6 along with the cancerization process from the HIOECs to the HB96 cells. Further validations in OSCC cellular and tissue levels confirm the decreased protein expression of S100A6 in the cancerous cell lines and cancerous tissues. These results suggest the decreased expression of S100A6 in OSCC, not only in vitro, but also in vivo.
Most of previous studies have reported the increased expression of S100A6 in many malignancies, such as colorectal carcinoma/adenocarcinoma, gastric cancer, pancreatic ductal adenocarcinoma, cutaneous melanoma, thyroid papillary carcinoma, astrocytoma, choleteatoma, osteosarcoma, acute myeloid leukemia, and craniopharyngioma (9-18). However, decreased expression of S100A6 has also been reported in prostate cancer, thyroid anaplastic carcinoma, breast cancer, hepatocellular carcinoma (10,11,14,19-21). In OSCC, increased S100A6 mRNA level has been reported by semi-quantitative reverse transcription-polymerase chain reaction (41), and decreased S100A6 mRNA level has also been reported by semiquantitative reverse transcription-PCR and quantitative real-time-PCR (42). No studies on protein expression of S100A6 in OSCC have been reported. In the present study, we found decreased expression of S100A6 in OSCC in both protein level and mRNA level, and both in cancerous cell line (compared with immortalized human oral epithelial cell line) and cancerous tissue (compared with paracancerous 
tissue from OSCC patients). Even though, large sample investigation is suggested in future studies.

Although, the precise mechanism is still not clear, S100A6 is involved in the cellular proliferation, regulation of actin cytoskeleton and $\beta$-catenin, membrane dynamics, p53 and heat-shock response. The targets of S100A6 include glyceraldehyde-3-phosphate dehydrogenase, p53, annexins (II, VI, XI), tropomyosin, caldesmon, calponin, lysozyme, calcyclin-binding protein/Siah-1-interacting protein, hop, sgt1, melusin, and kinesin light chain. However, the expression of S100A6 is regulated by DNA methylation, p53, nuclear transcription factor $\kappa \mathrm{B}$, platelet-derived growth factor, epidermal growth factor, tumor necrosis factor $\alpha$, retinoic acid, and some hormones (43). Further studies on the S100A6 detailed mechanism are clearly warranted.

\section{Acknowledgements}

This research was supported by grants 30973344 and 30700953 from National Natural Science Foundation of China; by grant 2007CG22 from Shanghai Educational Development Foundation; by grant 2007BAI18B03 from National Key Technology R\&D Program of China; by grant 08QA14056 from Shanghai Rising-Star Program; by grant $1052 \mathrm{~nm} 04700$ from Science and Technology Commission of Shanghai Municipality; and by grant Y2091171 from Natural Science Foundation of Zhejiang Province.

\section{References}

1. Kademani D: Oral cancer. Mayo Clin Proc 82: 878-887, 2007.

2. Parkin DM, Bray F, Ferlay J and Pisani P: Global cancer statistics, 2002. CA Cancer J Clin 55: 74-108, 2005.

3. Lenaerts K, Bouwman FG, Lamers WH, Renes J and Mariman EC: Comparative proteomic analysis of cell lines and scrapings of the human intestinal epithelium. BMC Genomics 8: 91, 2007.

4. Sdek P, Zhang ZY, Cao J, Pan HY, Chen WT and Zheng JW: Alteration of cell-cycle regulatory proteins in human oral epithelial cells immortalized by HPV16 E6 and E7. Int J Oral Maxillofac Surg 35: 653-657, 2006.

5. Zhong LP, Pan HY, Zhou XJ, et al: Characteristics of a cancerous cell line, HIOEC-B(a)P-96, induced by benzo(a)pyrene from human immortalized oral epithelial cell line. Arch Oral Biol 53: 443-452, 2008.

6. Kuznicki J, Kordowska J, Puzianowska M and Wozniewicz BM: Calcyclin as a marker of human epithelial cells and fibroblasts. Exp Cell Res 200: 425-430, 1992.

7. Filipek A, Puzianowska M, Cieslak B and Kuznicki J: Calcyclin$\mathrm{Ca}(2+)$-binding protein homologous to glial S-100 beta is present in neurons. Neuroreport 4: 383-386, 1993.

8. Yamashita N, Ilg EC, Schäfer BW, Heizmann CW and Kosaka T: Distribution of a specific calcium-binding protein of the S100 protein family, S100A6 (calcyclin), in subpopulations of neurons and glial cells of the adult rat nervous system. J Comp Neurol 404: 235-257, 1999.

9. Komatsu K, Andoh A, Ishiguro S, et al: Increased expression of S100A6 (Calcyclin), a calcium-binding protein of the S100 family, in human colorectal adenocarcinomas. Clin Cancer Res 6: 172-177, 2000.

10. Alvarez-Chaver P, Rodríguez-Piñeiro AM, Rodríguez-Berrocal FJ, Martínez-Zorzano VS and Páez de la Cadena M: Identification of hydrophobic proteins as biomarker candidates for colorectal cancer. Int J Biochem Cell Biol 39: 529-540, 2007.

11. Yang YQ, Zhang LJ, Dong H, et al: Upregulated expression of S100A6 in human gastric cancer. J Dig Dis 8: 186-193, 2007.

12. Vimalachandran D, Greenhalf W, Thompson C, et al: High nuclear S100A6 (Calcyclin) is significantly associated with poor survival in pancreatic cancer patients. Cancer Res 65: 3218-3225, 2005.
13. Shekouh AR, Thompson CC, Prime W, et al: Application of laser capture microdissection combined with two-dimensional electrophoresis for the discovery of differentially regulated proteins in pancreatic ductal adenocarcinoma. Proteomics 3: 1988-2001, 2003.

14. Brown LM, Helmke SM, Hunsucker SW, et al: Quantitative and qualitative differences in protein expression between papillary thyroid carcinoma and normal thyroid tissue. Mol Carcinog 45: 613-626, 2006

15. Camby I, Nagy N, Lopes MB, et al: Supratentorial pilocytic astrocytomas, astrocytomas, anaplastic astrocytomas and glioblastomas are characterized by a differential expression of S100 proteins. Brain Pathol 9: 1-19, 1999

16. Pelc P, Vanmuylder N, Lefranc F, et al: Differential expression of S100 calcium-binding proteins in epidermoid cysts, branchial cysts, craniopharyngiomas and cholesteatomas. Histopathology 42: 387-394, 2003 .

17. Luo X, Sharff KA, Chen J, He TC and Luu HH: S100A6 expression and function in human osteosarcoma. Clin Orthop Relat Res 466: 2060-2070, 2008.

18. Calabretta B, Kaczmarek L, Mars W, Ochoa D, Gibson CW, Hirschhorn RR and Baserga R: Cell-cycle-specific genes differentially expressed in human leukemias. Proc Natl Acad Sci USA 82: 4463-4467, 1985.

19. Rehman I, Cross SS, Azzouzi AR, et al: S100A6 (Calcyclin) is a prostate basal cell marker absent in prostate cancer and its precursors. Br J Cancer 91: 739-744, 2004.

20. Rehman I, Cross SS, Catto JW, et al: Promoter hyper-methylation of calcium binding proteins S100A6 and S100A2 in human prostate cancer. Prostate 65: 322-330, 2005.

21. Carlsson H, Petersson S and Enerbäck C: Cluster analysis of S100 gene expression and genes correlating to psoriasin (S100A7) expression at different stages of breast cancer development. Int J Oncol 27: 1473-1481, 2005.

22. Zhong LP, Chen WT, Zhang CP and Zhang ZY: Increased CK19 expression correlated with pathological differentiation grade and prognosis in oral squamous cell carcinoma patients. Oral Surg Oral Med Oral Pathol Oral Radiol Endod 104: 377-384, 2007.

23. Zhong LP, Yang X, Zhang L, et al: Overexpression of insulinlike growth factor binding protein 3 in oral squamous cell carcinoma. Oncol Rep 20: 1441-1447, 2008.

24. Sobin $\mathrm{LH}$ and Wittekind $\mathrm{CH}$ : International Union against cancer (UICC). In: TNM Classification of Malignant Tumours. 6th edition. Wiley-Liss, New York, pp22-26, 2002.

25. Barnes L, Eveson JW, Reichart P and Sidransky D: World Health Organization classification of tumours. In: Pathology and Genetics of Head and Neck Tumours. IARC Press, Lyon, pp168-175, 2005.

26. Livak KJ and Schmittgen TD: Analysis of relative gene expression data using real-time quantitative PCR and the $2-\Delta \Delta \Delta C$ t method. Methods 25: 402-408, 2001.

27. Zhong LP, Wei KJ, Yang X, et al: Increased expression of Annexin A2 in oral squamous cell carcinoma. Arch Oral Biol 54: 17-25, 2009.

28. Turhani D, Krapfenbauer K, Thurnher D, Langen H and Fountoulakis M: Identification of differentially expressed, tumorassociated proteins in oral squamous cell carcinoma by proteomic analysis. Electrophoresis 27: 1417-1423, 2006.

29. He QY, Chen J, Kung HF, Yuen AP and Chiu JF: Identification of tumor-associated proteins in oral tongue squamous cell carcinoma by proteomics. Proteomics 4: 271-278, 2004.

30. Lo WY, Tsai MH, Tsai Y, et al: Identification of over-expressed proteins in oral squamous cell carcinoma (OSCC) patients by clinical proteomic analysis. Clin Chim Acta 376: 101-107, 2007.

31. Koike H, Uzawa K, Nakashima D, et al: Identification of differentially expressed proteins in oral squamous cell carcinoma using a global proteomic approach. Int J Oncol 27: 59-67, 2005 .

32. Staab CA, Ceder R, Jägerbrink T, et al: Bioinformatics processing of protein and transcript profiles of normal and transformed cell lines indicates functional impairment of transcriptional regulators in buccal carcinoma. J Proteome Res 6: 3705-3717, 2007.

33. Huang X, Wei Y, Li L, et al: Serum proteomics study of the squamous cell carcinoma antigen 1 in tongue cancer. Oral Oncol 42: 26-31, 2006.

34. Cheng AJ, Chen LC, Chien KY, et al: Oral cancer plasma tumor marker identified with bead-based affinity-fractionated proteomic technology. Clin Chem 51: 2236-2244, 2005. 
35. Murase R, Abe Y, Takeuchi T, et al: Serum autoantibody to sideroflexin 3 as a novel tumor marker for oral squamous cell carcinoma. Proteomics Clin Appl 2: 517-527, 2008.

36. Wong DT: Towards a simple, saliva-based test for the detection of oral cancer 'oral fluid (saliva), which is the mirror of the body, is a perfect medium to be explored for health and disease surveillance'. Expert Rev Mol Diagn 6: 267-272, 2006.

37. Hu S, Yu T, Xie Y, et al: Discovery of oral fluid biomarkers for human oral cancer by mass spectrometry. Cancer Genomics Proteomics 4: 55-64, 2007.

38. Park NH, Gujuluva CN, Baek JH, et al: Combined oral carcinogenicity of HPV-16 and benzo(a)pyrene: an in vitro multistep carcinogenesis model. Oncogene 10: 2145-2153, 1995.

39. Rey O, Baluda MA and Park NH: Differential gene expression in neoplastic and human papillomavirus-immortalized oral keratinocytes. Oncogene 18: 827-831, 1999.
40. Kang MK, Kim RH, Kim SJ, et al: Elevated Bmi-1 expression is associated with dysplastic cell transformation during oral carcinogenesis and is required for cancer cell replication and survival. Br J Cancer 96: 126-133, 2007.

41. Berta GN, Ghezzo F, D'Avolio A, et al: Enhancement of calcyclin gene RNA expression in squamous cell carcinoma of the oral mucosa, but not in benign lesions. J Oral Pathol Med 26: 206-210, 1997.

42. Sapkota D, Bruland O, Bøe OE, Bakeer H, Elgindi OA, Vasstrand EN and Ibrahim SO: Expression profile of the S100 gene family members in oral squamous cell carcinomas. J Oral Pathol Med 37: 607-615, 2008.

43. Lesniak W, Slomnicki LP and Filipek A: S100A6, new facts and features. Biochem Biophys Res Commun 390: 1087-1092, 2009. 